\title{
Psychometric Evaluation of The Basic Psychological Need Satisfaction and Frustration Scale (BPNSFS) in Italy
}

\begin{tabular}{|r|l|}
\hline Journal: & Measurement and Evaluation in Counseling and Development \\
\hline Manuscript ID & MECD-15-07-048.R2 \\
\hline Manuscript Type: & Review \\
\hline Keywords: & $\begin{array}{l}\text { Reliability < Measurement, Convergent validity < Validity < Measurement, } \\
\text { Psychosocial development < Personality Assessment, Self Determination } \\
\text { Theory, Psychometric evaluation }\end{array}$ \\
\hline Abstract: & $\begin{array}{l}\text { Two studies were conducted to adapt the Basic Psychological Need } \\
\text { Satisfaction and Frustration Scale (BPNSFS) to the Italian context. Results } \\
\text { suggest that the BPNSFS can be considered a promising instrument in the } \\
\text { context of SDT-based research for investigating satisfaction and frustration } \\
\text { of the three basic needs in Italy. }\end{array}$ \\
\hline \multicolumn{2}{|l}{} \\
\hline
\end{tabular}

\section{SCHOLARONE}

Manuscripts 
Italian Psychometric Evaluation of BPNSFS 1

\title{
Psychometric Evaluation of the Basic Psychological Need Satisfaction and Frustration Scale (BPNSFS) in Italy
}

\author{
Summary \\ The purpose of the present multistudy report was to adapt the Basic Psychological Need \\ Satisfaction and Frustration Scale (BPNSFS) to the Italian context. Two studies were conducted. \\ In Study 1, we investigated the dimensionality, reliability, convergent and discriminant validity \\ of the instrument in a sample of 544 participants (Males $=41 \%$ ) aged from 16 to 35 years. In \\ Study 2, we replicated the results concerning dimensionality in an independent sample of 502 \\ participants (Males $=42 \%$ ) aged from 16 to 35 years. Furthermore, we analyzed measurement \\ invariance across gender. Results of both studies showed that comparing a series of competitive \\ factorial models, the six-factor (6-factor) model had the best fit to the data, assessing six \\ different but related dimensions: Autonomy Satisfaction, Autonomy Frustration, Relatedness \\ Satisfaction, Relatedness Frustration, Competence Satisfaction, and Competence Frustration. \\ Moreover, the reliability, convergent and discriminant validity may be considered adequate. \\ Finally, the BPNSFS showed to be invariant across gender. In sum, the BPNSFS can be \\ considered a promising instrument in the context of SDT-based research for investigating \\ satisfaction and frustration of the three basic needs in Italy. \\ Keywords: Need Satisfaction; Need Frustration; Self Determination Theory; Psychometric \\ evaluation; BPNSFS
}


Italian Psychometric Evaluation of BPNSFS 2

Self-determination theory (SDT; Deci \& Ryan, 1985; Ryan \& Deci, 2002) has become a popular framework for examining motivational issues in several contexts (e.g., Costa, Gugliandolo, Barberis, \& Larcan, 2014; Ng et al., 2012; Ryan \& Deci, 2013; Soenens \& Vansteenkiste, 2010). This is not surprising given that the approach to human development proposed within SDT accounts for the nature and function of motivation in conjunction with the psychological foundations from which motives develop. According to Ryan and Deci (2002), motivation varies along a regulatory continuum ranging from more controlled to fully selfdetermined processes, with the latter nurturing positive consequences such as task persistence and eudemonic well-being.

Within SDT, a critical issue in the effects of motivation concerns the degree to which people are able to satisfy three universal, innate, and nonhierarchical psychological needs, namely, autonomy, relatedness, and competence. The need for autonomy refers to volition and reflects the desire of individuals to be the origin or source of their own behavior (Deci \& Ryan, 1985) and is experienced when individuals perceive their behavior as self-endorsed (Ryan \& La Guardia, 2000). The need for competence refers to one's propensity to interact effectively with one's environment and to experience opportunities to exercise, as well as expressing one's capacities (Ryan \& La Guardia, 2000). The need for relatedness refers to feeling connected with significant others, to be loved, cared for, or that one belongs in a given social milieu. The fulfillment of these three basic needs leads to optimal behavior and psychological well-being.

Many studies have shown that the satisfaction of these basic psychological needs is positively associated with well-being (Rahman, Thøgersen-Ntoumani, Thatcher, \& Doust, 2011; Ryan, Bernstein, \& Brown, 2010; Wilson, Longley, Muon, Rodgers, \& Murray, 2006). Previous 
research has also indicated that low need satisfaction is related with various maladaptive outcomes, such as burnout, internalizing distress, unhealthy weight control behaviours, organizational deviance, and other negative affective states (e.g., Costa, Soenens, Gugliandolo, Cuzzocrea, \& Larcan, 2015; Inguglia, Ingoglia, Liga, Lo Coco, \& Lo Cricchio, 2014; Lian, Ferris, \& Brown, 2012; Reinboth, Duda, \& Ntoumanis, 2004; Thøgersen-Ntoumani, Ntoumanis, $\&$ Nikitaras, 2010). More recently researchers have begun to investigate the explanatory role of psychological need frustration in predicting ill-being and diminished human functioning (Bartholomew, Ntoumanis, Ryan, Bosch, \& Thøgersen-Ntoumani, 2011; Costa, Cuzzocrea, Gugliandolo, \& Larcan, 2016; Costa, Ntoumanis, Bartholomew, 2015).

In sum, within SDT need satisfaction and need frustration are considered to be crucial mechanisms in both optimal and no optimal functioning, helping to bridge the gap between pathology-oriented and strength-oriented frameworks and research. If low satisfaction of any of these needs can hamper growth, need frustration can be especially harmful and even pathogenic (e.g., Bartholomew et al. 2011a, b; Costa et al., 2015; Costa, Coppolino, \& Oliva, 2016).

To tap both the negative and positive experiential state that occurs when people perceive their psychological basic need satisfied and frustrated in their life, Chen et al. (2015) developed the Basic Psychological Need Satisfaction and Frustration Scale (BPNSFS), a 24-item scale that consists of six 4-item subscales assessing Autonomy satisfaction, Competence satisfaction, Relatedness satisfaction, Autonomy frustration, Competence frustration, and Relatedness frustration. Chen et al. (2015) tested and compared two competing factorial models of the BPNSFS. The 3-factor model included three correlated factors representing each of the needs, with satisfaction and frustration items loading together on the factor representing that need; the 6-factor model differentiated between a satisfaction and a frustration component within each of 
Italian Psychometric Evaluation of BPNSFS 4

the needs. The authors found evidence supporting the 6-factor structure of the BPNSFS. Moreover, they cross-validated the factor structure of the scale across four different national groups (USA, China, Peru, and Belgium), showing measurement invariance, as well as revealing an adequate internal consistency for each scale in the four countries that ranges between .64 and .89

In addition, the scale has also been validated with Portuguese high school students (Cordeiro, Paixão, Lens, \& Lacante, 2015) comparing a 6-factor model, two-factor model (Need satisfaction and Need frustration), and a hierarchical two-factor model ( $6^{2}$-factor), with 6 firstorder factors (Autonomy satisfaction, Autonomy frustration, Competence satisfaction, Competence frustration, Relatedness satisfaction, and Relatedness frustration) which served as indicators for 2 higher-order factors (Need satisfaction and Need frustration). Also in this case the 6-factor model yielded the best fit to the theoretical structure of the data.

Differently, Haerens, Aelterman, Vansteenkiste, Soenens, \& Van Petegem (2015) worked on a modified version of the BPNSFS suitable for investigating the needs with regard to physical activity in Belgian adolescents. They have found evidence for the hierarchical two-factor model $\left(6^{2}\right.$-factor), with 6 first-order and 2 higher-order factors.

However, few studies have analyzed the BPNSFS psychometric properties although it is becoming a widely used scale (Campbell et al., 2015; Haerens et al., 2015; Mabbe, Soenens, Vansteenkiste, \& Van Leeuwen, 2015). Furthermore, to date there are no studies that formally validated the BPNSFS in the Italian context. Dealing with these issues in Italy can be interesting because this country is traditionally characterized by a hierarchical, patriarchal, and interdependent cultural climate, which involves feelings of undue loyalty towards family members, hence Italian people could perceive the frustration of some needs (i.e., autonomy) as 
more normative and less harmful, carrying a different meaning to some need satisfaction or frustration items (Inguglia et al., 2015; Manzi, Vignoles, Regalia, \& Scabini, 2006).

The general purpose of the present study was to adapt the BPNSFS to the Italian cultural context and to evaluate its psychometric properties, investigating its dimensionality, reliability, convergent and discriminant validity. Since it was the first research conducted on the BPNSFS in Italy, it was structured in two different studies: the first one focused on the scale dimensionality, reliability, convergent and discriminant validity; the second one focused on the replication of results concerning dimensionality in an independent sample as well as on the analysis of gender differences in the dimensions of the BPNSFS.

\section{Study 1}

The first aim of Study 1 was to investigate the dimensionality of the Italian version of the BPNSFS. Specifically we compared a series of competitive factorial models. The one-factor model (1-factor) assumes a unidimensional structure, in which each item provides a measure of a single construct. It was tested in order to reject the hypothesis of unidimensionality of the BPNSFS. The three-factor model (3-factor) specifies three different but related dimensions: Autonomy, Relatedness and Competence. This model includes three latent factors representing each of the needs, with satisfaction and frustration items loading together on the factor representing that need (Chen et al., 2015). The six-factor model (6-factor) specifies six different but related dimensions: Autonomy satisfaction, Autonomy frustration, Relatedness satisfaction, Relatedness frustration, Competence satisfaction, and Competence frustration. This model supposes the existence of the three basic needs, as well as differentiating between a satisfaction and a frustration component within each of the three needs (Chen et al., 2015; Cordeiro et al., 2015). The hierarchical two-factor model ( $6^{2}$-factor) includes six first-order factors (Autonomy 
Italian Psychometric Evaluation of BPNSFS 6

satisfaction, Autonomy frustration, Competence satisfaction, Competence frustration, Relatedness satisfaction, and Relatedness frustration) loading on two higher-order factors (Need satisfaction and Need frustration) (Haerens et al., 2015). This model assumes that the dimensions of the scale are hierarchically organized into two superordinate levels or second-order factors, each representing need satisfaction or frustration. In turn, each superordinate level is defined by three subordinate levels, respectively the basic psychological needs. The hierarchical threefactor model $\left(6^{3}\right.$-factor) consists of six first-order factors (Autonomy satisfaction, Autonomy frustration, Relatedness satisfaction, Relatedness frustration, Competence satisfaction, and Competence frustration) and three second-order factors (Autonomy, Relatedness, and Competence). This model assumes that the dimensions of the scale are hierarchically organized into three superordinate levels, each representing one basic need. In turn, each superordinate level is defined by two subordinate levels, respectively the satisfaction and the frustration of the considered need. Alongside these models, a bi-factor model with one general factor and three specific factors (1+3 bifactor) may also be reasonably hypothesized (Holzinger \& Swineford, 1937; see also, Chen, West, \& Sousa, 2006). It assumes that each item load on two sets of factors: one representing the general component, linked to the general trait of need satisfaction/frustration, and one representing the specific component linked to the particular need involved in the item (Autonomy, Competence, or Relatedness). Globally, this model contains one general factor and three specific factors. Finally, it is also reasonable to hypothesize a $b i$ factor model with two general factors and three specific factors $(2+3$ bifactor). The difference with previous model is the existence of two general factors which distinguish Need satisfaction from Need frustration. So this model assumes that each item load on two sets of factors: one representing the general component (Need satisfaction or Need frustration), and one representing 
the specific component (Autonomy, Competence, or Relatedness). A rationale for the bifactor model could be an interest in obtaining an overall measure of need satisfaction/frustration factors as well as the single needs factors (autonomy, competence, and relatedness), and the bifactor model provides a direct parameterization of the measurement part of this fuller model within a confirmatory framework (Myers, Martin, Ntoumanis, Celimli, \& Bartholomew, 2014). On the basis of theoretical considerations framed on SDT, as well as on some studies which analyzed the structure of the scale (i.e., Chen et al., 2015; Cordeiro et al., 2015), we expected that the 6factor model yielded the best fit to the data.

The second aim of this study was to evaluate the reliability, convergent and discriminant validity of the scale. To test convergent and discriminant validity, the commonly criterion of Fornell-Larcker (1981) has been used. In latent variable modeling research, convergent and discriminant validity examine the extent to which indicators of a latent variable shared their variance and how they are different from others constructs in the same model. This procedure is widespread in the literature of structural equation modelling and is widely used in previous studies (Bagozzi \& Yi, 2012; MacKenzie, Podsakoff \& Podsakoff, 2011). Convergent and discriminant validity Fornell \& Larcker (1981), We expected that the BPNSFS would show adequate reliability, convergent and discriminant validity as in other studies which employed it (Campbell et al., 2015; Chen et al., 2015; Haerens et al., 2015).

\section{Method}

\section{Participants}

The original sample was composed of 616 Italian respondents aged from 16 and 35 years coming from the South of Italy. After the data screening (deletion of 44 cases with missing data on items, age and/or gender, of 19 cases identified as univariate outliers, and 9 cases identified as 
Italian Psychometric Evaluation of BPNSFS 8

multivariate outliers following the procedure described by Tabachnick \& Fidell, 1996), the final sample was comprised of 544 respondents (Males $=41 \%)$ aged from 16 to 35 years $(M=19.61$, $S D=3.18)$. With regard to occupational status, $44 \%$ were high school students, $45 \%$ were university students, $7 \%$ were of workers, and 4\% were unemployed. With regard to educational level, $61 \%$ held a lower secondary education diploma, 33\% held a high school diploma and 6\% of participants held a university degree.

\section{Procedure}

All participants voluntarily decided to take part in the research. Our convenience sample was recruited by soliciting volunteers through friends and appeals to community groups such as clubs, associations, and organizations in Sicily and Calabria (Italy) by a group of 20 postgraduate psychology students. The researchers asked several community groups to contact their affiliates to present the research project and directly contact some participants through friends and acquaintances. Participants were free to provide their willingness to complete the questionnaires. After describing the study purpose, participants signed the informed consent to participate in the study. Participants that aged under 18 completed the questionnaire after that their parents have signed the informed consent for them. The participants completed questionnaires under the supervision of an experimenter. Ethical approval for the study was granted by the relevant university ethics committee. Privacy and the anonymity of their answers were guaranteed. The questionnaires took about 10 minutes to complete.

\section{Instrument}

The original version of the BPNSFS was translated and adapted in Italian. We translated it from the original version and subsequently checked for similarity of items through the backtranslation procedure, according to the recommendations of the International Test commission 
(Hambleton, 2001). The scale was adapted from English to Italian by three independent translators. The translation team consisted of an English professor for Italian University class, an Italian professor of psychology, and a psychology $\mathrm{PhD}$ student with international background experiences. All the translators translated the measure from English to Italian. They discussed all the discrepancies identified between the two versions until finding a satisfactory solution. On this basis, a professional bilingual translator who did not have prior knowledge of the original versions then back-translated the Italian versions. The back-translation procedure from Italian to English proved to be identical in content with the original version of the BPNSFS. The Italian version of the scale is reported in Appendix.

The scale contains 24 items assessing the satisfaction and frustration of the psychological needs in one's life in general: Autonomy satisfaction (4 items; e.g., "I feel a sense of choice and freedom in the things I undertake"), Competence satisfaction (4 items; e.g., "I feel confident that I can do things well"), Relatedness satisfaction (4 items; e.g., "I feel that the people I care about also care about me"), Autonomy frustration (4 items; e.g., "I feel forced to do many things I wouldn't choose to do"), Competence frustration (4 items; e.g., "I have serious doubts about whether I can do things well"), and Relatedness frustration (4 items; e.g., "I feel that people who are important to me are cold and distant towards me"). Participants responded on a 5-point Likert scale ranging from 1 (completely disagree) to 5 (completely agree).

\section{Results}

\section{Descriptive Statistics and Correlation Coefficients}

Means, standard deviations, skewness, kurtosis, and range of observed scores of the BPNSFS items, and Pearson correlation coefficients are presented in Table 1. Data were normally distributed with skewness and kurtosis values ranging approximately from -1.0 to +1.0 
(Muthén \& Kaplan, 1985), with higher values reported on item 15. Skewness values ranged between -1.35 and 1.71; kurtosis values ranged between -.61 and 2.10. Inter-item correlations ranged from .04 to .72 in absolute value.

- Insert Table 1 about here -

\section{The BPNSFS Factorial Structure}

A series of Confirmatory Factor Analysis (CFA) was used to assess the BPNSFS factorial structure. CFA was performed on a covariance matrix using EQS 6.1 (Bentler, 2006). All models testing used maximum likelihood estimation method. In addition, robust statistics were used in order to account for the multivariate non-normality of variables (normalized estimate of Mardia coefficient $=7.80, p<.001)$; robust statistics included the Satorra-Bentler scaled $\chi^{2}$ test statistic $\left(\mathrm{SB} \chi^{2}\right)$ and robust Comparative Fit Index (CFI) (Satorra \& Bentler, 1994), both of which adjust standard errors to calculate parameter estimates in situations where multivariate normality cannot be assumed. A number of goodness of fit indexes were used to assess the fit of the model. The scale of the latent variables was determined by fixing at 1.0 their variances (with the only exception of the first-order factors in the $6^{3}$-factor model for which it was determined by fixing an anchor item for each factor). The goodness of fit indexes are given in Table 2. The 1-factor, 3factor and $1+3$ bifactor models had not a good fit to the data, while all other models fitted the data well. The comparison between models was made using the $\chi^{2}$ difference test (Satorra \& Bentler, 2001), the difference in CFI (Cheung \& Rensvold, 2002), and Akaike Information Criterion (AIC; Akaike, 1987). The best-fitting model was the 6-factor model as shown by all the selected indexes. We first compared the 6 -factor and $6^{2}$-factor models: the $\chi^{2}$ difference test was significant, $\square \chi^{2}(8)=116.60, p<.001$, the difference in CFI was meaningful, $\square$ CFI $=.02$, and AIC was lower for the 6-factor model than for the competing model; hence, the 6-factor model 
showed a better fit. We then compared the 6 -factor and $6^{3}$-factor models: the $\chi^{2}$ difference test was significant, $\square \chi^{2}(6)=93.08, p<.001$, the difference in CFI was meaningful, $\square \mathrm{CFI}=.02$, and AIC was lower for the 6-factor model than for the competing model; hence, the 6-factor model showed a better fit. We finally compared the 6 -factor and $2+3$ bifactor models: the $\chi^{2}$ difference test was significant, $\square \chi^{2}(13)=65.34, p<.001$, the difference in CFI was meaningful, $\square \mathrm{CFI}=$ .02 , and AIC was lower for the 6-factor model than for the competing model; hence, the 6-factor model showed a better fit.

The standardized solution of this model is reported in Figure 1. The examination of standardized estimates of factor loadings reveals that estimated parameters were substantial, robust standard errors were small and $t$-values were high and significant.

- Insert Table 2 about here -

- Insert Figure 1 about here -

\section{The BPNSFS Reliability, Convergent and Discriminant Validity}

We examined the coefficient $\rho_{i}$ derived by the CFA results to evaluate the single item reliability indicator (Fornell \& Larcker, 1981): $\rho_{i}$ values equal or higher than .50 may be considered acceptable (Bagozzi \& Yi, 2012). Figure 1 reports results. They showed that the majority of the items (67\%) exceeded the .50 threshold, detecting an adequate single item reliability. Less reliable items were: item 1 (Autonomy satisfaction), item 5 (Autonomy frustration), items 9 and 12 (Relatedness satisfaction), items 13, 14 and 16 (Relatedness frustration), and item 21 (Competence frustration).

We used the composite reliability indicator $\rho_{c}$ to evaluate the reliability of the constructs as it has been considered a better indicator than Cronbach's alpha (Fornell \& Larcker, 1981); values equal or higher than .70 may be considered acceptable (Carmines \& Zeller, 1979; 
Italian Psychometric Evaluation of BPNSFS 12

Nunnally, 1978). Table 3 reports results. They showed that the $\rho_{c}$ values exceeded the .70 threshold: they ranged from .77 (Relatedness frustration) to .87 (Competence satisfaction). Notwithstanding, we also computed Cronbach's alpha to allow a comparison with previous studies. Table 3 reports results. Values ranged ranged from .79 (Relatedness Satisfaction and Relatedness Frustration) to .85 (Competence Frustration).

The evaluation of convergent validity was performed by using the measurement developed by Fornell and Larcker (1981) known as the Average Variance Extracted (AVE). This measurement must exceed the value .50 , demonstrating that more than $50 \%$ of the variance of the construct is due to its indicators. Table 3 reports results. They showed that the AVE values were greater than the established reference value of .50, with the only exception of Relatedness frustration (.48) and Relatedness satisfaction (.46).

The evaluation of discriminant validity was performed by using the procedure developed by Fornell and Larcker (1981) based on the comparison between the AVE of each construct with the shared variance between constructs (represented by the square of the correlation between any two constructs, as reported in Figure 1). If AVE of each construct is greater than its shared variance with any other construct, discriminant validity is supported. Results showed that the AVE values were greater than shared variance with any other constructs. Taken together these results showed that the individual reliability of the items, the construct reliability, convergent and discriminant validity may be considered adequate.

- Insert Table 3 about here -

\section{Study 2}


The first aim of this study was to replicate the results of Study 1 about the dimensionality of the BPNSFS on an independent sample. The same series of competitive factorial models were compared. As in Study 1, we expected that the 6-factor model yielded the best fit to the data.

The second aim was to evaluate the measurement invariance of the BPNSFS across gender. Several studies have addressed the issues of gender differences in the basic needs (e.g., Adie, Duda, \& Ntoumanis, 2008; Chen et al., 2015; Gillet \& Rosnet, 2008; Ryan \& Deci, 2000), but no research has examined whether the BPNSFS has got a similar psychometric structure for males and females. In performing the measurement invariance testing procedure, we followed the previous and widely recommendations and guidelines (e.g. Cheung \& Rensvold, 2002; Vandenbergh \& Lance, 2000) who suggest to examine first measurement invariance (invariance of factor loadings, intercepts and uniquenesses) and then structural invariance (invariance of factor variances, covariances and means).

\section{Method}

\section{Participants and Procedure}

The original sample was composed of 589 Italian respondents aged from 16 and 35 years coming from the South of Italy. After the data screening (deletion of 59 cases with missing data on items, age and/or gender, of 19 cases identified as univariate outliers, and 9 cases identified as multivariate outliers following the procedure described by Tabachnick \& Fidell, 1996), the final sample was comprised of 502 respondents (Males $=42 \%)$ aged from 16 to 35 years $(M=19.76$, $S D=3.11)$. With regard to occupational status, $43 \%$ were high school students, $46 \%$ were university students, $7 \%$ were workers, and $4 \%$ were unemployed. With regard to educational level, 56\% held a lower secondary education diploma, 38\% held a high school diploma and 6\% of participants held a university degree. The same procedure of Study 1 was employed. 
Italian Psychometric Evaluation of BPNSFS 14

\section{Results}

\section{The BPNSFS Factor Structure}

The goodness of fit indexes of each model are given in Table 4. The 1-factor, 3-factor and $1+3$ bifactor models had not a good fit to the data, while all other models fitted the data well. The comparison between models was made using the $\chi^{2}$ difference test (Satorra $\&$ Bentler, 2001), the difference in CFI (Cheung \& Rensvold, 2002), and Akaike Information Criterion (AIC; Akaike, 1987). The best-fitting model was the 6-factor model as shown by all the selected indexes. We first compared the 6 -factor and $6^{2}$-factor models: the $\chi^{2}$ difference test was significant, $\square \chi^{2}(8)=$ 84.70, $p<.001$, the difference in CFI was meaningful, $\square \mathrm{CFI}=.02$, and AIC was lower for the 6factor model than for the competing model; hence, the 6-factor model showed a better fit. We then compared the 6-factor and $6^{3}$-factor models: the $\chi^{2}$ difference test was significant, $\square \chi^{2}(6)=$ 95.60, $p<.001$, the difference in CFI was meaningful, $\square \mathrm{CFI}=.03$, and AIC was lower for the 6factor model than for the competing model; hence, the 6-factor model showed a better fit. We finally compared the 6-factor and $2+3$ bifactor models: the $\chi^{2}$ difference test was significant, $\square \chi^{2}(13)=51.37, p<.001$, the difference in CFI was meaningful, $\square \mathrm{CFI}=.02$, and AIC was lower for the 6-factor model than for the competing model; hence, the 6-factor model showed a better fit.

- Insert Table 4 about here -

\section{The BPNSFS Measurement Invariance Across Gender}

After judging the fit of the 6-factor model in the sample as a whole, we examined the gender invariance for the model by running a multisample CFA. We tested five levels of group invariance, i.e. configural, metric, scalar, factor variances and covariances, and factor means invariance (Cheung \& Rensvold, 2002). Configural invariance was supported by a good fit for 
an unconstrained baseline model (M0) in which all parameters differed between males and females. Metric invariance was tested by comparing M0 with a model in which all factor loadings were simultaneously constrained across groups (M1). We then tested invariance in the item intercepts (M2), factor variances and covariances (M3), and factor means (M4), respectively, comparing M0 with models in which their respective parameters were constrained. For all tests, a significant deterioration in the model's fit would indicate noninvariance and would also lead to a significant Satorra-Bentler adjusted chi-square difference (Satorra \& Bentler, 2001). Because these chi-square difference tests detect small discrepancies with no practical or theoretical implications in sample sizes $>200$, we considered CFI decreases $\geq .010$ as more meaningful indicators (Chen, 2007; Cheung \& Rensvold, 2002). The goodness of fit indexes are given in Table 5.

The baseline model (M0) fit was acceptable. The comparison M1 vs. M0 showed a significant chi-square difference test, but worsening of CFI did not exceed the threshold of $\geq .010$, suggesting no meaningful group differences for factor loadings.

The comparison M2 vs. M0 showed a significant chi-square difference test and worsening of CFI exceeded the threshold of $\geq .010$, suggesting a meaningful group differences for item intercepts. The model was therefore modified releasing the equality constraints imposed on the intercept of item 9 ("I feel that the people I care about also care about me", Relatedness satisfaction) and item 23 ("I feel insecure about my abilities", Competence frustration). The comparison of the modified model M3 with M0 showed a significant chi-square difference test, but worsening of CFI did not exceed the threshold, suggesting a partial invariance of item intercepts. Specifically, the intercept for item 9 ("I feel that the people I care about also care about me", Relatedness satisfaction) was higher for males than for females, while the intercept 
Italian Psychometric Evaluation of BPNSFS 16

for item 23 ("I feel insecure about my abilities", Competence frustration) was lower for males than for females. Moreover, the Competence satisfaction mean was higher for males than for females, while the Competence frustration mean was lower for males than for females.

The comparison M3 vs. M0 showed a significant chi-square difference test, but worsening of CFI did not exceed the threshold of $\geq .010$, suggesting no meaningful group differences for factor variances and covariances.

The comparison M4 vs. M0 showed a significant chi-square difference test and worsening of CFI exceeded the threshold of $\geq .010$, suggesting a meaningful group differences for factor means. The model was therefore modified releasing the equality constraints imposed on the means of Competence satisfaction and Competence frustration. The comparison of the modified model M4 with M0 showed a significant chi-square difference test, but worsening of CFI did not exceed the threshold, suggesting a partial invariance of factor means. Globally, our results revealed a full metric invariance, a partial scalar invariance, a full factor variances and covariances invariance, and a partial factor means invariance.

- Insert Table 5 about here -

\section{Conclusions}

The importance of considering both need satisfaction and need frustration is well recognized within SDT (Bartholomew et al., 2011a; Costa et al., 2015). Consequently, the availability of a valid and reliable measure is paramount to help researchers to tap both the negative and positive experiential state that occurs when people perceive their psychological basic need satisfied and frustrated in their life. For this purpose, Chen et al. (2015) developed the BPNSFS. However, few studies have already investigated the psychometric properties of this scale (Chen et al., 2015; Campbell et al., 2015; Cordeiro et al., 2015). Thus, the main purpose of 
the current study was to adapt the BPNSFS to the Italian cultural context and to evaluate its psychometric properties, investigating its dimensionality, reliability, convergent and discriminant validity. Globally, the results of our studies provided evidence for the multidimensionality of the BPNSFS, as well as showing adequate reliability, convergent and discriminant validity of the scale.

Two studies investigated the latent structure of the scale comparing a series of competitive factorial models in independent samples: the one-factor (1-factor), the three-factor (3-factor), the six-factor (6-factor), the hierarchical two-factor $\left(6^{2}\right.$-factor), the hierarchical threefactor $\left(6^{3}\right.$-factor $)$, the bi-factor model with one general factor and three specific factors $(1+3$ factor), the bi-factor model with two general factor and three specific factors $(2+3$ factor $)$. In line with our hypothesis, the results of both studies showed that the 6-factor model had the best fit to the data. Although the 6-factor model was statistically the best, one of the two hierarchical models and one of the two bifactor models had also a good fit. To be able to choose the best model, some evidence of predictive validity would have been useful, to compare the relative predictive effects by the first order factors, the second-order factors, and the general and specific factors. With the presented information, there is no strong evidence for one particular type of model. Therefore, future research on PBNSF psychometric properties should test all three models using nomologically relevant outcome variables.

As shown by other scholars (e.g., Chen et al., 2015; Cordeiro et al., 2015) the BPNSFS items seem to assess six different but related dimensions: Autonomy Satisfaction, Autonomy Frustration, Relatedness Satisfaction, Relatedness Frustration, Competence Satisfaction, and Competence Frustration. Thus, our findings confirm the original intentions of the authors of the scale who wanted to develop a measure tapping into both the satisfaction and frustration of the 
three basic psychological needs. Moreover, our studies provided evidence that the items of the scale are understood similarly also by the Italian participants. Furthermore the mean scores of the BPNSFS dimensions were similar to those reported for the multi-ethnicity samples in Chen et al., (2015) (Autonomy Satisfaction range: 1.95 - 2.61, Autonomy Frustration range: 2.01 - 2.80; , Relatedness Satisfaction range: 3.42 - 4.24, Relatedness Frustration range: 3.86 - 4.43, Competence Satisfaction range: 1.48 - 2.14, and Competence Frustration range: 3.57 - 4.31 ). Also correlation between the BPNSFS dimensions and standardized factor loadings were similar to those reported in the study of Chen et al. (2015). The current findings also extend previous studies (Campbell et al., 2015; Chen, et al., 2015) by examining the structure of need satisfaction and need frustration within the Italian cultural climate, attesting to SDT's viewpoint that need satisfaction and need frustration are rather universal and thus relevant in all cultures, including Italy (Deci, \& Ryan 2000; Ryan, \& Deci 2002).

In general the results showed that the individual reliability of the items, the construct reliability, convergent and discriminant validity may be considered adequate, although few items, such as item 1 (Autonomy satisfaction), item 5 (Autonomy frustration), or item 12 (Relatedness satisfaction) were less reliable than others. As a matter of fact, the less reliability of some items can be overlooked because, as noted by Bagozzi and Yi (2012), «somewhat more emphasis might be placed on composite reliability [...] old standards for Cronbach's alpha and other formulae for reliability should not be applied rigidly to SEMs, and indeed focus should be placed more on the hypotheses under tests in, and goodness-of-fit of, any SEM» (p.17).

Finally, results of Study 2 showed a substantial measurement invariance across gender, revealing a full metric invariance, a partial scalar invariance, a full factor variances and covariances invariance, and a partial factor means invariance. Some differences related to gender 
have been highlighted; in particular, the intercept for item 9 ("I feel that the people I care about also care about me", Relatedness satisfaction) was higher for males than for females, while the intercept for item 23 ("I feel insecure about my abilities", Competence frustration) was lower for males than for females. Moreover, the Competence satisfaction mean was higher for males than for females, while the Competence frustration mean was lower for males than for females.

There are some limitations to these studies that are important to note. First, the construct validity of the scale was not tested. For instance, we did not analyze the relationships between the BPNSFS scores and some indicators of well-being or ill-being, as Chen et al. (2015). Future research to test construct validity of the measure in Italy is needed. Second, participants to our study are from Southern regions of Italy (Sicily and Calabria). Hence, they are not representative of the whole country, especially considering that in southern Italy the sense of relatedness is more valued than in northern Italy (Inguglia et al., 2015). Furthermore, in both studies, the majority of the sample is student-based, so it could not be representative of the population. Future study should try to generalize these results to different samples. Finally, future research should involve participants from different socioeconomic and cultural backgrounds (SES, ethnicity and educational level) given that our study, like most in this field, comprised relatively homogeneous samples of well-educated and White emerging adults.

Despite these limitations, our study contributes to the literature because it performs a validation process of this new need scale, that is very important in the context of SDT-based research, also in the Italian context. Thus, our research suggests that the BPNSFS is a valuable tool for investigating satisfaction and frustration of the three basic psychological needs among Italian adolescent and adults. In sum, the BPNSFS can be considered a promising instrument that deserves further investigation in terms of its psychometric properties in other European societies. 
Italian Psychometric Evaluation of BPNSFS 20

\section{References}

Adie, J., Duda, J. L., \& Ntoumanis, N. (2008). Autonomy support, basic need satisfaction and the optimal functioning of adult male and female sport participants: A test of basic needs theory. Motivation and Emotion, 32, 189-199. doi:10.1007/s11031-008-9095-z

Akaike, H. (1987). Factor analysis and AIC. Psychometrika, 52, 317-322.

Bagozzi, R. P., \& Yi, Y. (2012). Specification, evaluation, and interpretation of structural equation models. Journal of the Academic of Marketing Science, 40, 8-34. doi: 10.1007/ s11747-011-0278-x

Bartholomew, K. J., Ntoumanis, N., Ryan, R. M., \& Thogersen-Ntoumani, C. (2011a). Psychological need thwarting in the sport context: Assessing the darker sides of athletic experience. Journal of Sport and Exercise Psychology, 33, 75-102.

Bartholomew, K. J., Ntoumanis, N., Ryan, R. M., Bosch, J. A., \& Thøgersen-Ntoumani, C. (2011b). Self-determination theory and diminished functioning: The role of interpersonal control and psychological need thwarting. Personality and Social Psychology Bulletin, 37, 1459-1473. doi:10.1177/0146167211413125

Bentler, P. M. (2006). EQS 6 Structural equations program manual. Encino: CA. Multivariate Software Inc.

Campbell, R., Vansteenkiste, M., Delesie, L. M., Mariman, A. N., Soenens, B., Tobback, E., ... \& Vogelaers, D. P. (2015). Examining the role of psychological need satisfaction in sleep: A Self-Determination Theory perspective. Personality and Individual Differences, 77, 199-204. doi: dx.doi.org/10.1016/j.paid.2015.01.003

Carmines, E. G., \& Zeller, R. A. (1979). Reliability and validity assessment. Beverly Hills, CA: Sage. 
Chen, B., Vansteenkiste, M., Beyers, W., Boone, L., Deci, E. L., Van der Kaap-Deeder, J., ... \& Verstuyf, J. (2015). Basic psychological need satisfaction, need frustration, and need strength across four cultures. Motivation and Emotion, 39, 216-236. doi:10.1007/s11031-014-9450-1

Cheung, G. W., \& Rensvold, R. B. (2002). Evaluating goodness-of-fit indexes for testing measurement invariance. Structural Equation Modeling, 9, 233-255.

Cordeiro, P.M., Paixão, M.P., Lens, W., \& Lacante, M. (2015, under review). Motives for identity commitment and adjustment: the role of parenting, psychological needs and career decision-making self-efficacy. Psychologica Belgica.

Costa, S., Coppolino, P., \& Oliva, P. (2016). Exercise dependence and maladaptive perfectionism: the mediating role of basic psychological needs. International Journal of Mental Health and Addiction, 14, 241-256.

Costa, S., Cuzzocrea, F., Gugliandolo, M. C., \& Larcan, R. (2015). Associations between Parental Psychological Control and Autonomy Support, and Psychological Outcomes in Adolescents: The Mediating Role of Need Satisfaction and Need Frustration. Child Indicators Research, doi:10.1007/s12187-015-9353-z.

Costa, S., Gugliandolo, M.C., Barberis, N., \& Larcan, R. (2016). The Mediational role of psychological basic needs in the relation between conception of God and psychological outcomes. Journal of Religion And Health, 55(1), 1-15. doi:10.1007/s10943-014-9956-6

Costa, S., Ntoumanis, N., \& Bartholomew, K.J. (2015). Predicting the brighter and darker sides of interpersonal relationships: Does psychological need thwarting matter?. Motivation and Emotion, 39, 11-24. doi:10.1007/s11031-014-9427-0 
Italian Psychometric Evaluation of BPNSFS 22

Costa, S., Soenens, B., Gugliandolo, M.C., Cuzzocrea, F., \& Larcan, R. (2015). The mediating role of experiences of need satisfaction in associations between parental psychological control and internalizing problems: A study among Italian college students. Journal of Child and Family Studies, 24, 1106-1116. doi:10.1007/s10826-014-9919-2

Deci, E. L., \& Ryan, R. M. (1985). Intrinsic motivation and self-determination in human behavior. Springer Science \& Business Media.

Deci, E.L., \& Ryan, R.M. (2000). The "what" and "why" of goal pursuits: Human needs and the self-determination of behavior. Psychological Inquiry, 11, 227-268. doi: 10.1207/S15327965PLI1104_01

Deci, E. L., \& Ryan, R. M. (2002). Handbook of self-determination research. Rochester, NY: University of Rochester Press.

Fornell, C., \& Larcker, D.F. (1981). Evaluating structural equation models with unobservable variables and measurement error. Journal of Marketing Research, 18, 39-50.

Haerens, L., Aelterman, N., Vansteenkiste, M., Soenens, B., \& Van Petegem, S. (2015). Do perceived autonomy-supportive and controlling teaching relate to physical education students' motivational experiences through unique pathways? Distinguishing between the bright and dark side of motivation. Psychology of Sport and Exercise, 16, 26-36. doi: dx.doi.org/10.1016/j.psychsport.2014.08.013

Hambleton, R. K. (2001). The next generation of the ITC test translation and adaptation guidelines. European Journal of Psychological Assessment, 17, 164-172. doi: dx.doi.org/10.1027//1015-5759.17.3.164

Inguglia, C., Ingoglia, S., Liga, F., Lo Coco, A., \& Lo Cricchio, M. G. (2014). Autonomy and relatedness in adolescence and emerging adulthood: Relationships with parental support 
Italian Psychometric Evaluation of BPNSFS 23

and psychological distress. Journal of Adult Development, 22, 1-13. doi:10.1007/s10804-014-9196-8

Inguglia, C., Ingoglia, S., Liga, F., Lo Coco, A., Lo Cricchio, M. G., Musso, P., ... Lim, H. J. (2016). Parenting dimensions and internalizing difficulties in Italian and U.S. emerging adults: The intervening role of autonomy and relatedness. Journal of Child and Family Studies, 25(2), 419-431. doi:10.1007/s10826-015-0228-1

Lian, H., Ferris, D. L., \& Brown, D. J. (2012). Does taking the good with the bad make things worse? How abusive supervision and leader-member exchange interact to impact need satisfaction and organizational deviance. Organizational Behavior and Human Decision Processes, 117, 41-52.

Lirgg, C.D. (1991). Gender differences in self-confidence in physical activity: A meta-analysis of recent studies. Journal of Sport and Exercise Psychology, 13, 294-310.

Mabbe, E., Soenens, B., Vansteenkiste, M., \& Van Leeuwen, K. (2015). Do personality traits moderate relations between psychologically controlling parenting and problem behavior in adolescents?. Journal of Personality. doi:10.1111/jopy.12166.

MacKenzie, S. B., Podsakoff, P. M., \& Podsakoff, N. P. (2011). Construct measurement and validation procedures in MIS and behavioral research: Integrating new and existing techniques. MIS quarterly, 35, 293-334.

Manzi, C., Vignoles, V. L., Regalia, C., \& Scabini, E. (2006). Cohesion and enmeshment revisited: Differentiation, identity, and well-being in two European cultures. Journal of Marriage and Family, 68, 673-689. doi:10.1111/j.1741-3737.2006.00282.x 
Italian Psychometric Evaluation of BPNSFS 24

McDonough, M., \& Crocker, P.R. (2007). Testing self-determined motivation as a mediator of the relationship between psychological needs and affective and behavioral outcomes. Journal of Sport and Exercise Psychology, 29, 645-663.

McDonough, M. H., \& Crocker, P. R. (2007). Testing self-determined motivation as a mediator of the relationship between psychological needs and affective and behavioral outcomes. Journal of Sport \& Exercise Psychology, 29, 645-663.

Muthén, B., \& Kaplan, D. (1985). A comparison of methodologies for the factor analysis of nonnormal Likert variables. British Journal of Mathematical and Statistical Psychology, 38, 171-189.

Myers, N., Martin, J. Ntoumanis, N., Celimli, S., \& Bartholomew, K. (2014). Exploratory bifactor analysis in sport, exercise, and performance psychology: A substantivemethodological synergy. Sport, Exercise, and Performance Psychology, 3, 258-272.

Ng, J.Y., Ntoumanis, N., Thøgersen-Ntoumani, C., Deci, E. L., Ryan, R. M., Duda, J. L., \& Williams, G. C. (2012). Self-determination theory applied to health contexts a metaanalysis. Perspectives on Psychological Science, 7, 325-340. doi:10.1177/1745691612447309

Nunnally, J. (1978). Psychometric theory (2nd ed.). McGraw-Hill: New York.

Patrick, H., Knee, C.R., Canevello, A., \& Lonsbary, C. (2007). The role of need fulfillment in relationship functioning and well-being: a self-determination theory perspective. Journal of Personality and Social Psychology, 92, 434.

doi:dx.doi.org/10.1037/0022-3514.92.3.434

http://mc.manuscriptcentral.com/mecd 
Quested, E., \& Duda, J. L. (2010). Exploring the social-environmental determinants of well- and ill-being in dancers: A test of basic needs theory. Journal of Sport \& Exercise Psychology, 32, 39-60.

Rahman, R. J., Thogersen-Ntoumani, C., Thatcher, J., \& Doust, J. (2011). Changes in need satisfaction and motivation orientation as predictors of psychological and behavioural outcomes in exercise referral. Psychology \& Health, 26, 1521-1539. doi:10.1080/08870446.2010.538849

Reinboth, M., Duda, J. L., \& Ntoumanis, N. (2004). Dimensions of coaching behavior, need satisfaction, and the psychological and physical welfare of young athletes. Motivation and Emotion, 28, 297-313. doi:10.1023/B:MOEM.0000040156.81924.b8

Reis, H.T., Sheldon, K.M., Gable, S.L., Roscoe, J., \& Ryan, R.M. (2000). Daily well-being: The role of autonomy, competence, and relatedness. Personality and Social Psychology Bulletin, 26, 419-435. doi:10.1177/0146167200266002

Ryan, R.M., \& Deci, E.L. (2000). Self-determination theory and the facilitation of intrinsic motivation, social development, and well-being. American Psychologist, 55, 68. doi:10.1037//0003-066X.55.1.68

Ryan, R.M., \& Deci, E.L. (2013). Toward a social psychology of assimilation: Selfdetermination theory in cognitive development and education. In B.W. Sokol, F.M.E. Grouzet, U. Muller (Eds.), Self-regulation and autonomy: Social and developmental dimensions of human conduct (pp. 191-207). New York: Cambridge University Press.

Ryan, R. M., \& La Guardia, J. G. (2000). What is being optimized over development?: A selfdetermination theory perspective on basic psychological needs across the life span. In S. 
Italian Psychometric Evaluation of BPNSFS 26

Qualls \& N. Abeles (Eds.), Psychology and the aging revolution (pp. 145-172). Washington, DC: APA Books.

Ryan, R. M., Bernstein, J. H., \& Brown, K. W. (2010). Weekends, work, and well-being: Psychological need satisfactions and day of the week effects on mood, vitality, and physical symptoms. Journal of Social And Clinical Psychology, 29, 95-122. doi:10.1521/jscp.2010.29.1.95

Satorra, A., \& Bentler, P. M. (1994). Corrections to test statistics and standard errors in covariance structure analysis. In A. von Eye \& C.C. Clogg (Eds.), Latent variables analysis: Applications for developmental research (pp. 399-419). Thousand Oaks, CA: Sage.

Satorra, A., \& Bentler, P. M. (2001). A scaled difference chi-square test statistic for moment structure analysis , Psychometrika, 66, 507-514. doi:10.1007/BF02296192

Soenens, B., \& Vansteenkiste, M. (2010). A theoretical upgrade of the concept of parental psychological control: Proposing new insights on the basis of self-determination theory. Developmental Review, 30, 74-99. doi:10.1186/1479-5868-9-21.

Tabachnick, B. G., \& Fidell, L. S. (1996). Using multivariate statistics. Needham Heights, MA: Allyn \& Bacon.

Thøgersen-Ntoumani, C., Ntoumanis, N., \& Nikitaras, N. (2010). Unhealthy weight control behaviours in adolescent girls: A process model based on Self-Determination Theory. Psychology and Health, 25, 535-550

Vandenberg, R. J., \& Lance, C. E. (2000). A Review and Synthesis of the Measurement Invariance Literature: Suggestions, Practices, and Recommendations for Organizational Research. Organizational Research Methods, 3, 4-70. 
Italian Psychometric Evaluation of BPNSFS 27

Appendix A

Table A1

Italian version of the PBNS.

1. Sento un senso di possibilità di scelta e di libertà nelle cose in cui mi impegno

2. Sento che le mie decisioni rispecchino quello che voglio veramente

3. Sento che le mie scelte esprimono chi sono veramente

4. Sento che sto facendo quello che veramente mi interessa

5. La maggior parte delle cose che faccio, le faccio perchè "le devo fare"

6. Mi sento costretto a fare molte cose che io non avrei scelto di fare

7. Mi sento costretto a fare troppe cose

8. Le mie attività quotidiane mi sembrano come una catena di obblighi

9. Sento che le persone a cui tengo, tengono a me

10. Mi sento legato/a alle persone che si prendono cura di me e alle quali tengo

11. Mi sento vicino e in relazione con gli altri che sono importanti per me.

12. Provo un sentimento di calore con le persone con cui passo il mio tempo.

13. Mi sento escluso dal gruppo a cui voglio appartenere

14. Sento che le persone che sono importanti per me sono fredde e distanti nei miei confronti

15. Ho l'impressione che alle persone con cui passo il mio tempo, io non piaccia

16. Sento i miei rapporti interpersonali come superficiali.

17. Mi sento fiducioso di poter fare le cose bene

18. Mi sento capace in quello che faccio

19. Mi sento competente per raggiungere i miei obiettivi

20. Mi sento di poter completare con successo compiti difficili 
Italian Psychometric Evaluation of BPNSFS 28

21. Ho seri dubbi sul fatto che possa fare le cose bene

22. Mi sento deluso da molte delle mie prestazioni

23. Mi sento insicuro delle mie capacità

24. Mi sento un fallimento a causa degli errori che faccio 
Figure 1. Standardized solution of the 6-correlated factor model. $618 \times 437 \mathrm{~mm}(72 \times 72 \mathrm{DPI})$ 
Table 1

Mean, standard deviation (SD), skewness (S), and kurtosis (K) of BPNSFS ttems and Pearson correlation coefficients (Study I, $n=344)$.

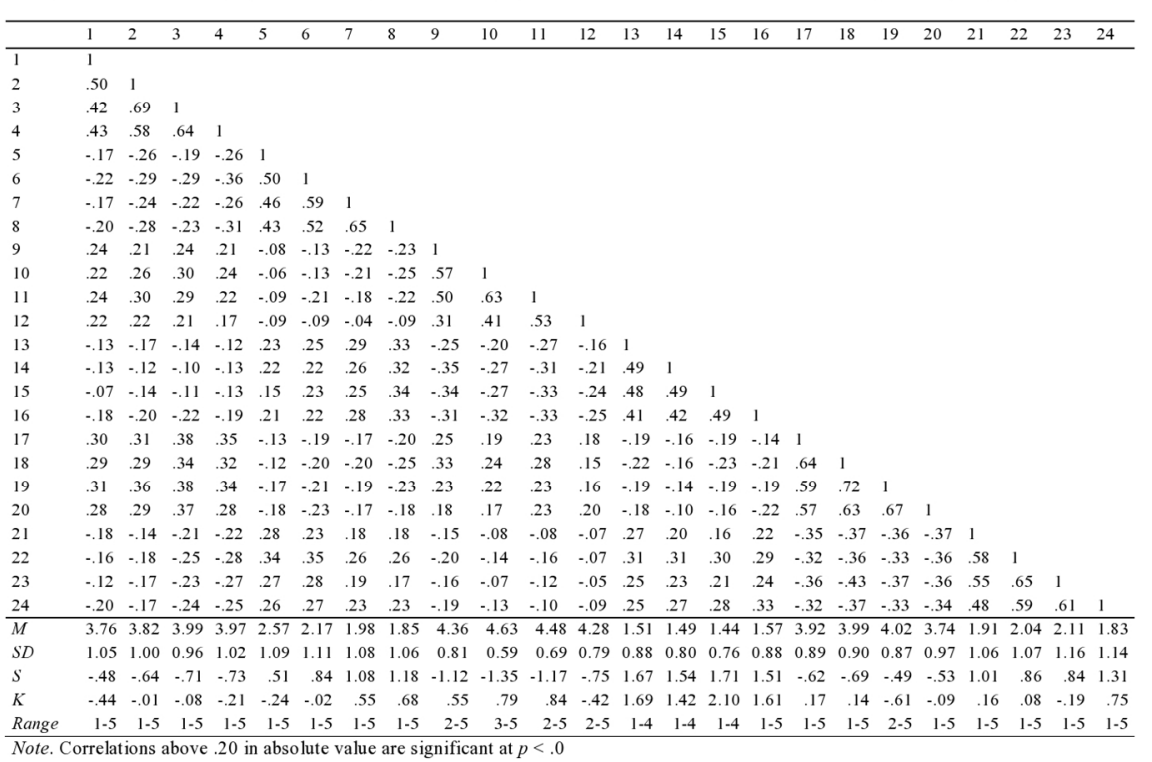

29

30

31

32

Table 1

Mean, standard deviation (SD), skewness (S), and kurtosis (K) of BPNSFS items and Pearson correlation coefficients (Study $1, \mathrm{n}=544$ ).

$582 \times 449 \mathrm{~mm}(72 \times 72$ DPI $)$ 
Table 2

Summary of goodness of fit indexes for CFA models (Study 1, $n=544$ ).

\begin{tabular}{|c|c|c|c|c|c|c|c|c|}
\hline & $x^{2}$ & $\mathrm{df}$ & $\mathrm{SB} \chi^{2}$ & CFI & SRMR & RMSEA & RMSEA $90 \%$ CI & AIC \\
\hline 1-factor model & 3049.60 & 252 & $2358.15^{\mathrm{m}}$ & .55 & .12 & .12 & $.12-.13$ & 1854.15 \\
\hline 3- factor model & $1890.47^{+\ldots+\infty}$ & 249 & $1474.06^{n+\infty}$ & .74 & .10 & .09 & $.09-.10$ & 976.06 \\
\hline 6- factor model & $469.96^{* \ldots *}$ & 237 & $379.75^{* s+*}$ & .97 & .04 & .03 & $.03-.04$ & -94.24 \\
\hline \multicolumn{9}{|l|}{ Hierarchical models } \\
\hline $6^{3}$-factor hierarchical model & $577.41^{\mathrm{sk \kappa}}$ & 243 & $467.35^{N * *}$ & .95 & .06 & .04 & $.04-.05$ & -18.65 \\
\hline $6^{2}$-factor hierarchical model & $604.62^{* * 4 k}$ & 245 & $489.63^{\text {k*k*k }}$ & .95 & .06 & .04 & $.04-.05$ & -0.37 \\
\hline \multicolumn{9}{|l|}{ Bifactor models } \\
\hline $1+3$ bifactor model & $972.88^{\mathrm{suk}}$ & 225 & $770.42^{\text {senk }}$ & .88 & .05 & .07 & $.06-.07$ & .320 .42 \\
\hline $2+3$ bifactor model & $574.28^{* k k}$ & 224 & $471.99^{\text {knot* }}$ & .95 & .05 & .04 & $.04-.05$ & 23.99 \\
\hline
\end{tabular}

Table 2

Summary of goodness of fit indexes for CFA models (Study $1, n=544$ ).

$618 \times 437 \mathrm{~mm}(72 \times 72 \mathrm{DPI})$

http://mc.manuscriptcentral.com/mecd 
Table 3

Composite reliability ( $\rho_{c}$ ) and Average Variance Extraxted (AVE) in the 6-factor model, and

Cronbach's alpha (Study 1, $n=544)$.

Table 3

Composite reliability ( $\rho c)$ and Average Variance Extraxted (AVE) in the 6- factor model, and Cronbach's alpha (Study $1, \mathrm{n}=544$ ).

$437 \times 618 \mathrm{~mm}(72 \times 72 \mathrm{DPI})$ 
Table 4

Summary of goodness of fit indexes for CFA models (Study 2, $n=502$ ).

\begin{tabular}{|c|c|c|c|c|c|c|c|c|}
\hline & $x^{2}$ & $\mathrm{df}$ & $\mathrm{SB} \chi^{2}$ & CFI & SRMR & RMSEA & RMSEA $90 \%$ CI & AIC \\
\hline 1-factor model & $2816.70^{\mathrm{nt}}$ & 252 & $2148.82^{\cdots \cdots}$ & .53 & .12 & .12 & $.12-.13$ & 1644.82 \\
\hline 3- factor model & $1884.13^{\text {ton }}$ & 249 & $1452.52^{\ldots+\infty}$ & .70 & .10 & .10 & $.10-.11$ & 954.52 \\
\hline 6- factor model & $453.55^{\circ \cdots *}$ & 237 & $365.12^{\text {wnst }}$ & .97 & .04 & .03 & $.03-.04$ & -108.88 \\
\hline \multicolumn{9}{|l|}{ Hierarchical models } \\
\hline $6^{-3}$-factor hierarchical model & $588.73^{\mathrm{s \kappa \kappa}}$ & 243 & $472.33^{\mathrm{ms} *}$ & .94 & .06 & .04 & $.04-.05$ & -13.67 \\
\hline $6^{2}$-factor hierarchical model & $565.24^{2 \times * k}$ & 245 & $454.12^{\text {kest }}$ & .95 & .06 & .04 & $.04-.05$ & -35.88 \\
\hline \multicolumn{9}{|l|}{ Bifactor models } \\
\hline $1+3$ bifactor model & $905.13^{\mathrm{sk \textrm {k }}}$ & 225 & $728.20^{\text {kektk }}$ & .88 & .05 & .07 & $.06-.07$ & 278.20 \\
\hline $2+3$ bifactor model & $530.67^{2 * k k}$ & 224 & $432.44^{\text {sets }}$ & .95 & .05 & .04 & $.04-.05$ & -15.56 \\
\hline
\end{tabular}

Table 4

Summary of goodness of fit indexes for CFA models (Study $2, n=502$ ).

$618 \times 437 \mathrm{~mm}(72 \times 72$ DPI $)$

http://mc.manuscriptcentral.com/mecd 
Table 5

\begin{tabular}{|c|c|c|c|c|c|c|c|c|c|c|}
\hline & $x^{2}$ & df & $\mathrm{SB} \chi^{2}$ & CFI & SRMR & RMSEA & $\begin{array}{l}\text { RMSEA } \\
90 \% \text { CI }\end{array}$ & $\Delta \chi^{2}$ & $\Delta \mathrm{df}$ & $\triangle \mathrm{CCFI}$ \\
\hline M0 Configural invariance & 838.21 & 474 & $664.21^{\circ 00}$ & .943 & .05 & .05 & $.04-.06$ & - & - & - \\
\hline M1 Metric invariance & $906.19^{\text {ckent }}$ & 498 & $728.19^{\operatorname{ses}}$ & .936 & .12 & .05 & $.05-.06$ & $75.67^{* * * *}$ & 24 & .007 \\
\hline M2 Scalar invariance & $951.67^{7+m e t}$ & 516 & $769.72^{\circ * *}$ & .931 & .10 & .05 & $.05-.06$ & $119.72^{* * *}$ & 42 & .012 \\
\hline M2a Partial scalar invariance & $928.24^{(\text {tatent }}$ & 514 & $758.36^{\cos }$ & .935 & .10 & .05 & $.05-.05$ & $116.28^{* * * *}$ & 40 & .008 \\
\hline M3 Factor variance/covariance invariance & $947.40^{\text {kest }}$ & 529 & $793.65^{\mathrm{ses}}$ & .934 & .11 & .05 & $.05-.06$ & $180.29^{* s s}$ & 55 & .009 \\
\hline M4 Factor means invariance & $972.07^{\text {mate }}$ & 535 & $783.93^{0.00}$ & .931 & .12 & .05 & $.05-.06$ & $125.19^{\text {nek }}$ & 61 & .012 \\
\hline M4a Partial factor mcans invariance & $955.31^{\mathrm{ken}}$ & 533 & $762.34^{n=8}$ & .934 & .11 & .05 & $.05-.06$ & $99.06^{m * *}$ & 59 & .009 \\
\hline
\end{tabular}

Table 5

Multigroup tests of the measurement invariance across gender (males $=210$ vs. females $=292$ ).

$618 \times 437 \mathrm{~mm}(72 \times 72 \mathrm{DPI})$ 